\title{
Dynamics of stakeholder relations with multi-person aggregation
}

\begin{abstract}
Purpose: The primary aim of this paper is to develop a novel method to analyse dynamic interactions of stakeholders to explain how a set of agents can act by considering the power/influence positions.

Design/methodology/approach: A novel mathematical application uses the importance of characteristics algorithm in combination with composition max-min to compare, group and order information according to the importance of its characteristics. The mathematical application is focused on a strategic analysis, evaluating stakeholder dynamics through power relationships.
\end{abstract}

Findings: The results show a comparison of the relationships among each of the stakeholders to obtain the relative intensity and importance of relationships between them, given by the fuzzy matrix $\mathrm{FRIn}_{\mathrm{M}}$ and the fuzzy matrix $\mathrm{FRI}_{\mathrm{M}}$, respectively. This application provides a useful tool for a dynamic analysis of stakeholders in a complex environment, where the best approach to performing a strategic analysis process is sought.

Limitations/Implications: the main implication of the proposed approach is taking into account the importance of information to establish the boundaries and relationships of each characteristic according to its intensity. However, limitations are due to the nature of this research, based on theoretical assumptions regarding stakeholders and the use of a hypothetical example to show the operation of algorithms.

Original/value: The primary advantage of this proposition is that it takes into account the importance of information to establish the relationships among the characteristics according to their intensity. Additionally, it performs multiple comparisons among each characteristic of the information. The interests and opinions of decision makers can be parameterised. A mathematical application shows how each interest group could be classified and related according to subjective information.

Keywords: Decision-making, Strategy, Fuzzy relation, Stakeholder, Power/Influence.

Paper type: Research paper 


\section{Introduction}

The stakeholder theory has helped researchers to understand the dynamics of the interaction between a firm and its environment. This theory has tried to explain and predict how organisations should act by considering the influences of stakeholders (Wagner et al., 2011) on planning and decision-making. The stakeholder analysis is essentially descriptive, normative and instrumental (Donaldson and Preston, 1995; Friedman and Miles, 2002). Accordingly, numerous authors have proposed various analysis methods that explain relations between stakeholders (Friedman and Miles, 2006; Frooman, 1999; Jones, 1995; Savage et al., 2011; Wagner et al., 2012). Such methods analyse stakeholders' relationships via visual diagrams that can help comprehend, simplify and aggregate complex information (Fassin, 2007). A widely accepted graphical representation is Freeman's stakeholder model. Freeman (1984, 2004, 2011) has proposed an approach for obtaining an aggregate view of the relationships between a firm and a set of actors around it. Nonetheless, Freeman's model has been criticised for being a static representation that does not consider changes over time and heterogeneity of factors (Fassin, 2009; Friedman and Miles, 2002).

Several approaches have been suggested to remedy the above deficiencies by considering networks and interactions. One of them is a network approach to explaining interactions among stakeholders. This approach suggests a broader perspective, going beyond the dyadic linkages between the firm and each stakeholder (Rowley, 1997). Furthermore, it focuses on the firm's response to the influence of its stakeholders and considers multiple and interdependent interactions that simultaneously exist in stakeholder environments (Rowley, 1997). However, this approach does not explain how relationships within the network could vary in the context of threats and opportunities created by changes in the environment (Friedman and Miles, 2002). Thus, dynamic and changing relationships among stakeholders are complex due to changes in the environment.

Indeed, the dynamics and changes in stakeholder's relationships have critical impacts on an entity's chain of responsibility, the importance and status of stakeholders (Fassin, 2010). Furthermore, the subjectivity of the observer performing the stakeholder analysis directly influences the results. Considering the above, several theories, e.g., dynamic capabilities, game theory and cooperation theory, are being used to model stakeholder dynamics and improve strategic analysis and decision-making processes in business and economics (Windsor, 2011). Thus, by relying on a descriptive analysis of stakeholders, it is possible to develop a methodological perspective using fuzzy techniques of decision-making under uncertainty. Such techniques could help improve the dynamic analysis of stakeholder theory, as they are capable of representing the importance of information and established relationships.

The literature on decision-making under uncertainty includes a wide range of methods capable of processing subjective and objective information, personal preferences, attitudes and the resulting data (GilLafuente and Merigó, 2007; Gil-Lafuente et al., 2013; Herrera et al. 1995; Martinez and Herrera, 2000; Wei, 2009), which are being applied to economics and business management (Gil-Aluja, 2000; Kaufmann et al., 1994; Kaufmann and Gil-Aluja, 1993, 1995) to improve strategic decision-making within a complex environment. On the one hand, there is an effective technique that can guide a comparison process (Merigó and Gil-Lafuente, 2010, 2011). This technique is related to distance measures, developed in GilAluja, (1999), Gil-Lafuente (2002), Kaufmann and Gil-Aluja (1986, 1987) and Merigó (2009), which enable the decision maker to compare various different aspects of available information. On the other hand, other techniques based on the incidence concept (Kaufmann and Gil-Aluja, 1988) can enable analysis of relationships and their ordering, e.g., to identify causality among relationships, link relationships and order them according to importance of their characteristics (Gil-Aluja, 1999). Indeed, incidence is a subjective concept that is difficult to measure and is rarely properly justified, as it is related to subjective attributes. Accordingly, such techniques can enable analysis of the relevant subjective attributes, i.e., to perform an appraisal of the decision maker according to certain notable characteristics. The opinion of the decision maker is more significant in such an analysis than in other methodologies. The decision maker offers its estimates based on the quality or quantity of data received, statistics, reports and information from surveys, all of which are used to guide its decisions. Hence, such techniques enable decision makers to analyse dynamic relationships between each stakeholder and the firm according to the importance of 
each and to define strategic courses of action. Furthermore, the firm's relationships are established be 3 tween individuals (either senior management or a group of employees selected to represent employees' shared interests) and linked through certain characteristics to different levels of importance. Thus, the links between each of them can be strengthened or weakened by variations in the intensity of relations (Blanco-Mesa, 2015).

The above perspective has been used by several authors to apply this methodology in business and economics, e.g., marketing (Gil-Lafuente, 1997; Nicolás and Gil-Lafuente, 2012), customer relationship management (Gil-Lafuente and Luis Bassa, 2011), strategy (Gil-Lafuente and Barcellos de Paula, 2010), stakeholders (Gil-Lafuente and Barcellos de Paula, 2013), corporate social responsibility (Vizuete Luciano et al., 2013), economics (Blanco-Mesa and Gil-Lafuente, 2017; Blanco-Mesa and Gil-Lafuente, 2014; Gil-Lafuente et al., 2012; León-Castro et al., 2016, 2017; Pérez-Arellano et al., 2017), entrepreneurship (Blanco-Mesa et al., 2017; Maqueda Lafuente et al., 2013) and sport business (Gil-Lafuente, 2002,

2008; Gil-Lafuente et al., 2012), showing its utility for decision-making under uncertainty. The above applications have the advantage that the appraisal of the decision maker involves assessments of several alternatives, intensities and the importance of relationships. Thus, this methodology allows subjective attributes to be represented relative to strategic decision-making in business and economics problems.

The primary objective of the paper is to develop a novel method for analysing dynamic interactions of stakeholders to explain how a set of agents can act by considering the power/influence positions. This method applies the importance of characteristics algorithm together with composition max-min to compare, group and order information. A mathematical application is focused on strategic analyses for evaluating stakeholder dynamics through power relationships. The primary advantages of this proposition are that a) it takes into account the importance of information to establish the relationships among the characteristics according to their intensity, $b$ ) it performs multiple comparisons among each characteristic of the information, c) the interests and opinions of decision makers can be parameterised, and d) the mathematical application shows how each interest group could be classified and related according to subjective information. This application provides a useful tool for a dynamic analysis of stakeholders in a complex environment, and it provides the best method of performing a strategic analysis process. This paper is organised as follows. Section 2 reviews the basic concepts of comparison indices' representation in a square fuzzy matrix and fuzzy composition. Section 3 develops a strategic analysis technique for evaluating stakeholder dynamics. Section 4 presents a mathematical application focused on the power attribute of stakeholder relationships. Section 5 presents the summary and the primary conclusion.

\section{Preliminaries}

In this Section, we briefly review several basic concepts related to the distance notion and a fuzzy relation composed of the importance of characteristics representation in a square fuzzy matrix and fuzzy composition.

\subsection{The comparison indices' representations in a square fuzzy matrix}

Links between relations are used in decision-making under uncertainty to establish the incidence or causality of a relation through the details of relation levels. The levels can be given by subjective attributes that in turn can be parameterised by comparison indices. Therefore, the results obtained by comparison indices can be represented on a square fuzzy matrix.

\subsubsection{The ordering according to the importance of characteristics algorithm}

The importance of characteristics (Gil-Aluja, 1999) is a useful technique for establishing the relative importance in a causality relation between two objects by considering their characteristics. The im- 
portance of characteristics algorithm involves the reciprocal matrix, the dominant eigenvalue and the dominant eigenvector.

Definition 1. The reciprocal matrix $[\tilde{R}]$ collects all comparisons of characteristics performed by the time it has been preferred. A binary comparison is performed for each characteristic $C_{j}$, i.e., involving $C_{i}, C_{k} ; i, k=1,2, \ldots, n$ using a quotient, which determines the time that such characteristic is preferred to the other, such that

$$
\mu_{i k}=\frac{f_{i}}{f_{k}} \quad, \quad i, k=1,2, \ldots, n,
$$

where $C_{i}$ represents the times it is preferred to $C_{k}$.

Note that the matrix comprises the collection of all $\mu_{i k}$ and is both reciprocal and coherent/consistent. It is reciprocal because it satisfies the following conditions: $\mu_{i i}=1 ; \mu_{i k}=1 / \mu_{k i}$, where $\mu_{i k} \in R_{o}^{+}, i, k=$ $1,2, \ldots, n$. It is coherent/consistent because it satisfies the following criteria: $\forall i, k, l \in\{1,2, \ldots, n\}$; $f_{i} / f_{k} * f_{k} / f_{l}=f_{i} / f_{l}$, i.e. $\mu_{i k} * \mu_{k l}=\mu_{i l}$.

Therefore, the matrix must satisfy the transpose property, given by:

$$
\sum_{k=1}^{n} \mu_{i k} * f_{k}=\sum_{k=1}^{n} \frac{f_{i}}{f_{k}} * f_{k}=n * f_{i},
$$

and the proportionality property, given by:

$$
\frac{\mu_{i k}}{\mu_{l k}}=\frac{f_{i} / f_{k}}{f_{l} / f_{k}}=\frac{f_{i}}{f_{l}}
$$

Additionally:

$$
\frac{\mu_{i k^{\prime}}}{\mu_{l k^{\prime}}}=\frac{f_{i} / f_{k^{\prime}}}{f_{l} / f_{k^{\prime}}}=\frac{f_{i}}{f_{l}},
$$

Therefore:

$$
\frac{\mu_{i k}}{\mu_{l k}}=\frac{\mu_{i k^{\prime}}}{\mu_{l k^{\prime}}} .
$$

Definition 2. The dominant eigenvalue $E_{v a}$ of dimension $\mathrm{n}$ is a mapping $E_{v a}:[0,1]^{n} x[0,1]^{n} \rightarrow[0,1]$ that has an associated limit weighting vector $\lambda_{1}^{(c)}$, with $w_{j} \in[0,1]$ and $\sum_{j=1}^{n} w_{j} \geq 1$, such that:

$$
E_{v a}\left(\left\langle x_{\mathrm{i}}, y_{\mathrm{k}}\right\rangle, \ldots,\left\langle x_{n}, y_{m}\right\rangle\right)=\sum_{k=1}^{n} \max _{j}\left(\mu_{i k} * y_{\mathrm{k}}\right),
$$

where $x_{i}$ and $y_{k}$ represent the jth largest of sets $X$ and $Y$, respectively.

Therefore,

$$
\lambda_{1}^{(c)}=E_{v a} \max
$$

Definition 3. The dominant Eigenvector $V^{(c)}$ has an associated weighting vector $\lambda_{1}^{(c)}$, with $w_{j} \in[0,1]$ and $\sum_{j=1}^{n} w_{j} \leq 1$, such that

$$
V^{c}\left(\left\langle x_{\mathrm{i}}, y_{\mathrm{k}}\right\rangle, \ldots,\left\langle x_{n}, y_{m}\right\rangle\right)=\sum_{k=1}^{n} \frac{\left(\mu_{\left.i k^{*} y_{\mathrm{k}}\right)}\right.}{\max \left(\mu_{\left.i k^{*} y_{\mathrm{k}}\right)}\right.}
$$

while the normalised form is defined by:

$$
N^{(c)}=\frac{V^{(c)}}{\sum V^{(c)}} .
$$


Therefore, the relative importance is shown by each characteristic within a representation of the importance matrix $[\tilde{R}]$. This matrix is given by:

$$
[\tilde{R}]^{*}=N^{(c)} *[\tilde{R}],
$$

where $[\tilde{R}]$ is the $i t h$ argument of set $\mathrm{X}$.

Hence, following the above process, a matrix $[\tilde{R}]$ that represents a square fuzzy matrix is obtained. This matrix satisfies all of the following properties: being reflexive, transitive, symmetric and fuzzy anti-symmetric.

It is reflexive because the relation of elements of set $x \in E$ with itself, i.e., with $x \in E$ is total, while the elements along the main diagonal are all equal to 1 . Therefore, it must hold that $\forall a_{i} \in E$, where $i=1,2, \ldots, n: \mu_{i j}=1, i=j$ and $\mu_{i j} \in[0,1], i \neq j$, where $a_{i}$ are the $i$ th arguments of set $\mathrm{E}$.

It is transitive because the indirect relation between three elements of the referential $E\left(a_{i}, a_{j}, a_{k}\right)$ can be considered in the same manner, i.e., the indirect relation between $a_{i}$ and $a_{k}$ cannot be greater than the direct relation between $a_{j}$ and $a_{k}$. Therefore it must hold that $\forall a_{i}, a_{j}, a_{k} \in E: \mu_{a i k} \geq \vee\left(\mu_{a i a j} \wedge\right.$ $\left.\mu_{a j a k}\right)$.

It is symmetric because the intensity of the relation from $a_{i}$ to $a_{j}$ is considered to be the same as that from $a_{j}$ to $a_{i}$. Therefore, it must hold that $\forall a_{i}, a_{j} \in E, a_{i} \neq a_{j}$ and $\mu_{a i}=\mu_{a j}$, where $a_{i}$ and $a_{j}$ are the ith arguments of set $\mathrm{E}$.

It is fuzzy anti-symmetric because the intensity of the relation from $a_{i}$ to $a_{j}$ is not considered to be the same as from $a_{j}$ to $a_{i}$. Therefore it must hold that $\forall a_{i}, a_{j} \in E, a_{i} \neq a_{j}$ and $\mu_{i j} \neq \mu_{j i}$ or $\mu_{i j}=\mu_{j i}=0$ where $a_{i}$ and $a_{j}$ are the $i t h$ arguments of the set E.

\subsection{Fuzzy composition}

Fuzzy composition or convolution max-min (Gil-Aluja, 1999) is a useful technique for associating physical and mental objects. In decision-making under uncertainty, it is used to represent the degree of belonging or the lack of association and the interaction or interconnection of fuzzy relation between elements of the set itself or two or more fuzzy sets. For elements of the set itself, or two or more fuzzy sets, the convolution max-min can be defined as follows:

Definition 4. A fuzzy composition $R \circ S$ is defined as a fuzzy relation $U x W$, and it is associated with the respective characteristic functions $\mu_{R}(x, y)$ and $\mu_{S}(y, z)$, which are given by the composition maxmin, such that

$$
\mu_{R \circ S}(x, z)=\vee_{y \in V}\left(\mu_{\mathrm{R}}(x, y) \wedge \mu_{\mathrm{s}}(y, z)\right),
$$

where $(x, z) \in(\mathrm{U}, \mathrm{W})$.

Therefore, the relative intensity is established by the convolution of fuzzy matrix $[\tilde{R}]$ with itself. The behaviour of relation can be observed through evolution over time or along the time axis.

Definition 5. The max-min composition of matrix $[\tilde{R}]$ is given by:

$$
\begin{aligned}
& {[\tilde{R}] \circ[\tilde{R}]=[\tilde{R}]^{2}} \\
& {[\tilde{R}] \circ[\tilde{R}] \circ[\tilde{R}]=[\tilde{R}]^{3} \circ[\tilde{R}]=[\tilde{R}]^{4} .}
\end{aligned}
$$

Therefore:

$$
[\tilde{R}] \circ[\tilde{R}]=[\tilde{R}]^{n} \circ[\tilde{R}]=[\tilde{R}]^{n+1},
$$


when $[\tilde{R}]^{n}=[\tilde{R}]^{n+1}$ the process is terminates.

\section{A strategic analysis process for evaluating stakeholder dynamics}

In this section, we present a rational process for evaluating the stakeholder dynamics. We describe the strategic analysis approach.

The use of ordering according to the importance of characteristics and fuzzy composition max-min in a dynamic relationship analysis of stakeholders within a specific environment allows aggregating, ordering and linking information. The dynamics and changes in relationships of each stakeholder have a crucial impact on an entity's chain of responsibility, the salience and status of stakeholders (Fassin, 2010).

The firm reacts to the influence of its stakeholders and considers multiple and interdependent interactions that simultaneously exist in stakeholder environments (Rowley, 1997). The introduction of importance of characteristics and linking relationships can reflect the dynamics of stakeholders' relations according to the preference of each characteristic. A similar process has been developed by Gil-Lafuente and Barcellos de Paula (2013) and Gil-Lafuente et al. (2012a; 2012b), resulting in instruments that can be applied to the comparison, ordering and linking process. The strategic analysis process consists of five steps. They are described as follows:

Step 1. Analyse and determine the salient characteristics for each stakeholder. Theoretically, the result will be represented as $\mathrm{C}=\left\{\mathrm{C}_{1}, \mathrm{C}_{2}, \ldots, \mathrm{C}_{\mathrm{i}}, \ldots, \mathrm{C}_{\mathrm{n}}\right\}$, where $\mathrm{C}_{\mathrm{i}}$ is the $i$ th characteristic of each stakeholder to be considered.

Step 2. Estimate the level of preference for each characteristic to form a reciprocal matrix category (see Tables 3 and 4), where $\mathrm{P}$ is the preference condition of stakeholders expressed by a subset, $\mathrm{C}_{\mathrm{i}}$ is the $i$ th characteristic to be considered and $l_{i} \in[0,1] ; i=1,2, \ldots, n$ is the quotient that determines the time of preference for the ith characteristic.

Note that the importance of characteristics is assessed through a multi-person analysis, where several experts provide opinions. To this effect, we can use a wide range of aggregation operators including a weighted average, an ordered weighted average (OWA) (Yager, 1988), a weighted ordered weighted average (WOWA) (Merigó, 2011; Torra, 1997; Xu and Da, 2003), a probabilistic weighted average (Merigó, 2013; Merigó et al., 2016) and unified aggregation operators (Merigó et al., 2015).

Definition 6. A weighted average is defined by:

$$
W A\left(C_{1}{ }^{i}, C_{2}{ }^{i}, \ldots, C_{n}^{i}\right)=\sum_{h=1}^{m} v_{h} C_{h}^{i},
$$

where $C_{h}{ }^{i}$ is the importance given by the $h t h$ expert about the ith characteristic, and $v_{h}$ is the importance of the hth expert with $v_{h} \in[0,1]$ with $\sum_{h=1}^{m} v_{h}=1$.

Note that if $v_{h}=1 / \mathrm{m}$, all experts are equally important to the analysis, and the multi-person aggregation is performed via an arithmetic average. However, we may encounter scenarios where the experts' importance is unknown. Thus, we need to use a different approach to aggregating data, e.g., with the OWA operator.

Definition 7. The OWA operator considers a parameterised family of aggregation operators between the minimum and the maximum, as follows:

$$
O W A\left(C_{1}{ }^{i}, C_{2}{ }^{i}, \ldots, C_{n}{ }^{i}\right)=\sum_{j=1}^{m} w_{j} b_{j}
$$


where $b_{j}$ is the $j$ th largest of the $C_{h}{ }^{i}$, and $w_{j} \in[0,1]$ with $\sum_{j=1}^{m} w_{j}=1$.

Note that a more general approach could be developed by using the WOWA operator (also known as OWAWA operator) in the following way:

Definition 8. WOWA operator is defined as follow:

$$
\text { WOWA }\left(C_{1}{ }^{i}, C_{2}{ }^{i}, \ldots, C_{n}{ }^{i}\right)=\sum_{j=1}^{m} \hat{v}_{j} b_{j},
$$

where $b_{j}$ is the $j$ th largest of the $C_{h}{ }^{i}$, each characteristic $C_{h}{ }^{i}$ has an associated weight $v_{h}$ with $\sum_{h=1}^{m} v_{h}=1$ and $v_{h} \in[0,1], \hat{v}_{j}=\beta w_{j}+(1-\beta) v_{j}$ with $\beta \in[0,1], v_{j}$ is the weight $v_{h}$ ordered according to $b_{j}$, that is, according to the $j$ th largest of the $C_{h}{ }^{i}$, and $w_{j} \in[0,1]$ with $\sum_{j=1}^{m} w_{j}=1$, representing the OWA weights.

Note that if $\beta=1$, the WOWA operator is identical to OWA, while if $\beta=0$, we obtain a weighted average. Numerous other extensions could be developed in the same manner, following the current developments in the aggregation operator literature (Emrouznejad and Marra, 2014; Yager et al., 2011; Zeng et al., 2012).

Step 3. Determine the criteria levels of importance for each stakeholder and the current environment to form the actual condition of each stakeholder (see Tables 5 and 6), where Q is the level of importance according to a fuzzy subset, $\mathrm{C}_{\mathrm{i}}$ is the $i$ th characteristic to be considered and $\mathrm{k}_{\mathrm{i}} \in[0,1] ; \mathrm{i}=1,2, \ldots, \mathrm{n}$ is the valuation, a number between 0 and 1 , of the ith characteristic.

Note that in this new approach with a multi-person analysis, the level of importance can be obtained in two different ways. The first is the classical method by which we only add a previous calculation in Step 2 by aggregating the experts' information. This is the common process for all aggregation operators mentioned. However, in case of the weighted average, it is also possible to have all processes analysed by different experts, obtaining a level of importance for each stakeholder and for each expert. Having obtained such information, we aggregate the data of experts, forming a collective level of importance that is equivalent to that of the classical method.

Step 4. Determine eigenvalues and eigenvectors in order to find the dominant eigenvalue and the dominant eigenvector. In this step, the largest eigenvalue and the dominant eigenvector are used to establish a fuzzy relative importance matrix, which is used to define a fuzzy relative intensity matrix.

Step 5. Strategic decisions are made according to results obtained during the preceding steps. In the final step, the decision as to the strategy position of the stakeholder network should be made. It is worth noting that adoption of strategic decisions is based on analysing the position that best fits the firm's interests.

\section{A numerical example}

In this section, we present an application of the new approach proposed above. The primary advantage of using the ordering importance of characteristics algorithm and linking relationships is being able to parameterise the importance of information for each characteristic and order characteristics according to the intensity of relation. The application is focused on use of attributes, i.e., characteristics, for evaluating stakeholder dynamics. The design of the proposed approach consists of three steps, as follows:

Step 1. The attributes (Mitchell et al. 1997) of each stakeholder category (Fassin, 2009) are determined from the perspective of a group of experts. Based on the specific circumstances of the firm's immediate environment, it is assumed that senior management wants to analyse the relationships with specific stake- 
holders according to the dominance of the power/influence $(\mathrm{P})$ characteristic. Similarly, it is also assumed that senior management wants to consider the importance of the firm's environment $\left(\mathrm{L}_{\mathrm{IE}}\right)$, defined according to stakeholder categories: $R_{S}$ being the genuine stakeholders, $S_{W}$ being the stake-watchers and $S_{K}$ representing the stake-keepers (see Table 1). Each characteristic of the set of stakeholders is considered a property. This first step allows us to make a holistic appraisal of the firm's immediate environment, as it takes into account each category and subset of stakeholders around the firm.

Table 1. Characteristics and categories of each stakeholder group

\begin{tabular}{|c|c|c|c|c|}
\hline Category & & Stakeholders & Kind of relation & Characteristic \\
\hline \multirow{6}{*}{$\begin{array}{c}\text { Real } \\
\text { Stakeholders }\end{array}$} & $a$ & Firm & Growth business & $\mathrm{P}$ \\
\hline & $b$ & Employees & Labour laws & $\mathrm{P}$ \\
\hline & $c$ & Business & Contracts and agreements & $\mathrm{P}$ \\
\hline & $d$ & Financers & Owners or investors & $\mathrm{P}$ \\
\hline & $e$ & Customers & Users, customers & $\mathrm{P}$ \\
\hline & $f$ & Communities and Society & Local government, Location, community & $\mathrm{P}$ \\
\hline \multirow{5}{*}{ Stakewatchers } & $g$ & Unions and association & Unions and Safety groups & $\mathrm{P}$ \\
\hline & $h$ & Competitors & Marked, competitors & $\mathrm{P}$ \\
\hline & $i$ & Institutions and Auditors & Institutional investors & $\mathrm{P}$ \\
\hline & $j$ & Customers Associations & Customer advocate group & $\mathrm{P}$ \\
\hline & $k$ & Public interest Public & Public interest group & $\mathrm{P}$ \\
\hline \multirow{5}{*}{ Stakekeepers } & $l$ & Local and national organization & Business activities control & $\mathrm{P}$ \\
\hline & $m$ & Media and others & Diffuser and observer & $\mathrm{P}$ \\
\hline & $n$ & International Commission & Ranking agencies and security analysts & $\mathrm{P}$ \\
\hline & $o$ & Government state & Legal activities control & $\mathrm{P}$ \\
\hline & $p$ & Civil Society & Civil, environmental and human rights advocates & $\mathrm{P}$ \\
\hline
\end{tabular}

Step 2. The level of preference for each characteristic is determined to define the reciprocal matrix category. Here, each estimate of a characteristic could be composed of a quality- or quantity-related dataset, i.e., statistics, reports and information from surveys, all of which are as guidance by the CEO. It is assumed that senior management suggests the estimates of the power characteristic for each stakeholder (see Table 3) to define the subjective preference matrix for each stakeholder (see Table 4). Note that information is assessed by a group of five experts that gives their opinion about the results. We assume that the five experts are equally important. Thus, we use an arithmetic average to aggregate their information. In other words, following Eq. 14, we use $V=(0,2 ; 0,2 ; 0,2 ; 0,2$; $0,2)$. The results are shown in Tables 2 and 3.

Table 2. Estimation of the characteristics according to the opinion given by the experts

\begin{tabular}{ccccccccccccccccc}
\hline Stakeholder & $a$ & $b$ & $c$ & $d$ & $e$ & $f$ & $g$ & $h$ & $i$ & $j$ & $k$ & $l$ & $m$ & $n$ & $o$ & $p$ \\
\hline Power - Expert 1 & 0,9 & 0,3 & 0,9 & 0,6 & 0,5 & 0,6 & 0,3 & 0,6 & 0,9 & 0,3 & 0,6 & 0,7 & 0,7 & 0,5 & 0,8 & 0,6 \\
Power - Expert 2 & 1 & 0,5 & 0,7 & 0,9 & 0,8 & 0,7 & 0,5 & 0,8 & 0,7 & 0,4 & 0,7 & 0,8 & 0,6 & 0,9 & 0,8 & 0,9 \\
Power - Expert 3 & 0,8 & 0,6 & 0,8 & 0,9 & 0,7 & 0,8 & 0,2 & 0,8 & 0,8 & 0,4 & 0,3 & 0,7 & 0,7 & 0,8 & 0,6 & 0,7 \\
Power - Expert 4 & 0,8 & 0,3 & 0,7 & 0,7 & 0,8 & 0,4 & 0,5 & 0,5 & 0,5 & 0,3 & 0,4 & 0,9 & 0,8 & 0,7 & 0,9 & 0,6 \\
Power - Expert 5 & 1 & 0,3 & 0,9 & 0,9 & 0,7 & 0,5 & 0,5 & 0,8 & 0,6 & 0,1 & 0,5 & 0,9 & 0,7 & 0,6 & 0,9 & 0,7 \\
\hline
\end{tabular}

Table 3. Estimation of the characteristics - Collective results

\begin{tabular}{ccccccccccccccccc}
\hline Stakeholder & $a$ & $b$ & $c$ & $d$ & $e$ & $f$ & $g$ & $h$ & $i$ & $j$ & $k$ & $l$ & $m$ & $n$ & $o$ & $p$ \\
\hline Power & 0,9 & 0,4 & 0,8 & 0,8 & 0,7 & 0,6 & 0,4 & 0,7 & 0,7 & 0,3 & 0,5 & 0,8 & 0,7 & 0,7 & 0,8 & 0,7 \\
\hline
\end{tabular}


Table 4. Subjective preference matrix

\begin{tabular}{ccccccccccccccccc}
\hline & $a$ & $b$ & $c$ & $d$ & $e$ & $f$ & $g$ & $h$ & $i$ & $j$ & $k$ & $l$ & $m$ & $n$ & $o$ & $p$ \\
\hline$a$ & 1 & 2,25 & 1,13 & 1,13 & 1,29 & 1,50 & 2,25 & 1,29 & 1,29 & 3,00 & 1,80 & 1,13 & 1,29 & 1,29 & 1,13 & 1,29 \\
$b$ & 0,44 & 1 & 0,50 & 0,50 & 0,57 & 0,67 & 1,00 & 0,57 & 0,57 & 1,33 & 0,80 & 0,50 & 0,57 & 0,57 & 0,50 & 0,57 \\
$c$ & 0,89 & 2,00 & 1 & 1,00 & 1,14 & 1,33 & 2,00 & 1,14 & 1,14 & 2,67 & 1,60 & 1,00 & 1,14 & 1,14 & 1,00 & 1,14 \\
$d$ & 0,89 & 2,00 & 1,00 & 1 & 1,14 & 1,33 & 2,00 & 1,14 & 1,14 & 2,67 & 1,60 & 1,00 & 1,14 & 1,14 & 1,00 & 1,14 \\
$e$ & 0,78 & 1,75 & 0,88 & 0,88 & 1 & 1,17 & 1,75 & 1,00 & 1,00 & 2,33 & 1,40 & 0,88 & 1,00 & 1,00 & 0,88 & 1,00 \\
$f$ & 0,67 & 1,50 & 0,75 & 0,75 & 0,86 & 1 & 1,50 & 0,86 & 0,86 & 2,00 & 1,20 & 0,75 & 0,86 & 0,86 & 0,75 & 0,86 \\
$g$ & 0,44 & 1,00 & 0,50 & 0,50 & 0,57 & 0,67 & 1 & 0,57 & 0,57 & 1,33 & 0,80 & 0,50 & 0,57 & 0,57 & 0,50 & 0,57 \\
$h$ & 0,78 & 1,75 & 0,88 & 0,88 & 1,00 & 1,17 & 1,75 & 1 & 1,00 & 2,33 & 1,40 & 0,88 & 1,00 & 1,00 & 0,88 & 1,00 \\
$i$ & 0,78 & 1,75 & 0,88 & 0,88 & 1,00 & 1,17 & 1,75 & 1,00 & 1 & 2,33 & 1,40 & 0,88 & 1,00 & 1,00 & 0,88 & 1,00 \\
$j$ & 0,33 & 0,75 & 0,38 & 0,38 & 0,43 & 0,50 & 0,75 & 0,43 & 0,43 & 1 & 0,60 & 0,38 & 0,43 & 0,43 & 0,38 & 0,43 \\
$k$ & 0,56 & 1,25 & 0,63 & 0,63 & 0,71 & 0,83 & 1,25 & 0,71 & 0,71 & 1,67 & 1 & 0,63 & 0,71 & 0,71 & 0,63 & 0,71 \\
$l$ & 0,89 & 2,00 & 1,00 & 1,00 & 1,14 & 1,33 & 2,00 & 1,14 & 1,14 & 2,67 & 1,60 & 1 & 1,14 & 1,14 & 1,00 & 1,14 \\
$m$ & 0,78 & 1,75 & 0,88 & 0,88 & 1,00 & 1,17 & 1,75 & 1,00 & 1,00 & 2,33 & 1,40 & 0,88 & 1 & 1,00 & 0,88 & 1,00 \\
$n$ & 0,78 & 1,75 & 0,88 & 0,88 & 1,00 & 1,17 & 1,75 & 1,00 & 1,00 & 2,33 & 1,40 & 0,88 & 1,00 & 1 & 0,88 & 1,00 \\
$o$ & 0,89 & 2,00 & 1,00 & 1,00 & 1,14 & 1,33 & 2,00 & 1,14 & 1,14 & 2,67 & 1,60 & 1,00 & 1,14 & 1,14 & 1 & 1,14 \\
$p$ & 0,78 & 1,75 & 0,88 & 0,88 & 1,00 & 1,17 & 1,75 & 1,00 & 1,00 & 2,33 & 1,40 & 0,88 & 1,00 & 1,00 & 0,88 & 1 \\
\hline
\end{tabular}

Step 3. The levels of importance of each stakeholder and the current environment, defining the actual condition of each stakeholder is to be determined. It is assumed that a group of experts suggest the level of importance of each stakeholder and category (see Tables 5 and 6) based on external information and the experts' experience and criteria.

Table 5. Level of importance for each stakeholder

\begin{tabular}{ccccccccccccccccc}
\hline Stakeholder & $a$ & $b$ & $c$ & $d$ & $e$ & $f$ & $g$ & $h$ & $i$ & $j$ & $k$ & $l$ & $m$ & $n$ & $o$ & $p$ \\
\hline $\mathbf{L}_{\text {IS }}$ & 0,09 & 0,04 & 0,08 & 0,08 & 0,07 & 0,06 & 0,04 & 0,07 & 0,07 & 0,03 & 0,05 & 0,08 & 0,07 & 0,07 & 0,08 & 0,07 \\
\hline
\end{tabular}

Table 6. Level of importance of the environment

\begin{tabular}{|c|c|c|c|c|c|c|c|c|c|c|c|c|c|c|c|c|}
\hline & $a$ & $b$ & $c$ & $d$ & $e$ & $f$ & $g$ & $h$ & $i$ & $j$ & $k$ & $l$ & $m$ & $n$ & $o$ & $p$ \\
\hline Category & \multicolumn{5}{|c|}{ Real Stakeholders } & & \multicolumn{5}{|c|}{ Stakewatchers } & \multicolumn{5}{|c|}{ Stakekeepers } \\
\hline $\mathrm{L}_{\mathrm{IE}}$ & & & & & & & 0,3 & 0,7 & 0,5 & 0,2 & 0,7 & 0,7 & 0,7 & 0,2 & 0,8 & 0,7 \\
\hline
\end{tabular}

\subsection{Results}

The primary results of fuzzy matrix calculation that allow establishing the importance and intensity relations among stakeholders are shown as follows: the relative level of importance $\left(\mathrm{RL}_{\mathrm{I}}\right)$ is obtained by multiplication of each level of importance of each stakeholder $\left(\mathrm{L}_{\mathrm{IS}}\right)$ and the level of importance of the environment $\left(\mathrm{L}_{\mathrm{IE}}\right)$ of each stakeholder category (see Table 7). To determine the dominant eigenvalue $\left(\mathrm{E}_{\mathrm{va}}\right)$ and the dominant eigenvector $\left(\mathrm{V}^{(\mathrm{c})}\right)$, the main fuzzy matrix is multiplied by $\mathrm{RL}_{\mathrm{I}}$ (see Table 8 ). To determine the fuzzy relative importance matrix $\left(\mathrm{FRI}_{\mathrm{M}}\right)$, the main fuzzy matrix is multiplied by normalised $\mathrm{V}^{(\mathrm{c})}$ (see Table 9), while to obtain the fuzzy relative intensity matrix $\left(F R n_{M}\right), F R I_{M}$ is processed through the max-min composition (see Table 10). Finally, Figures 1 and 2 show visual diagrams of the resulting linking relationship and its intensity.

Table 7. Relative level of importance

\begin{tabular}{|c|c|c|c|c|c|c|c|c|c|c|c|c|c|c|c|c|}
\hline & \multicolumn{5}{|c|}{$\mathbf{R}_{\mathbf{S}}$} & \multicolumn{6}{|c|}{$\mathbf{S}_{\mathrm{W}}$} & \multicolumn{5}{|c|}{$\mathbf{S}_{\mathbf{K}}$} \\
\hline & $a$ & $b$ & $c$ & $d$ & $e$ & $f$ & $g$ & $h$ & $i$ & $j$ & $k$ & $l$ & $m$ & $n$ & $o$ & $p$ \\
\hline $\mathrm{L}_{\mathrm{IS}}$ & 0,09 & 0,04 & 0,08 & 0,08 & 0,07 & 0,06 & 0,04 & 0,07 & 0,07 & 0,03 & 0,05 & 0,08 & 0,07 & 0,07 & 0,08 & 0,07 \\
\hline $\mathrm{L}_{\mathrm{IE}}$ & \multicolumn{6}{|c|}{0,7} & 0,3 & 0,7 & 0,5 & 0,2 & 0,7 & 0,7 & 0,7 & 0,2 & 0,8 & 0,7 \\
\hline $\mathrm{RL}_{\mathrm{I}}$ & 0,06 & 0,03 & 0,05 & 0,05 & 0,05 & 0,04 & 0,01 & 0,05 & 0,03 & 0,01 & 0,03 & 0,05 & 0,05 & 0,01 & 0,06 & 0,05 \\
\hline
\end{tabular}


Table 8. Eigenvector and Eigenvalue

\begin{tabular}{lcccccccccccccccc}
\hline & $a$ & $b$ & $c$ & $d$ & $e$ & $f$ & $g$ & $h$ & $i$ & $j$ & $k$ & $l$ & $m$ & $n$ & $o$ & $p$ \\
\hline$\left(\mathrm{E}_{\mathrm{va}}\right)$ & 16,000 & 7,111 & 14,222 & 14,222 & 12,444 & 10,667 & 7,111 & 12,444 & 12,444 & 5,333 & 8,889 & 14,222 & 12,444 & 12,444 & 14,222 & 12,444 \\
$\left(\mathrm{~V}^{\text {(c) }}\right)$ & 1 & 0,444 & 0,889 & 0,889 & 0,778 & 0,667 & 0,444 & 0,778 & 0,778 & 0,333 & 0,556 & 0,889 & 0,778 & 0,778 & 0,889 & 0,778 \\
$(\mathrm{~N})$ & 0,086 & 0,038 & 0,076 & 0,076 & 0,067 & 0,057 & 0,038 & 0,067 & 0,067 & 0,029 & 0,048 & 0,076 & 0,067 & 0,067 & 0,076 & 0,067 \\
\hline
\end{tabular}

N Note that the dominant eigenvector has been normalized $(\mathrm{N})$ to determine the weight of each stakeholder. Notation: Dominant Eigenvalue $\left(\mathrm{E}_{\mathrm{va}}\right)$; Dominant Eigenvector $\left(\mathrm{V}^{(\mathrm{c})}\right)$; Normalizing $(\mathrm{N})$.

Table 9. Fuzzy relative importance matrix

\begin{tabular}{rccccccccccccccccc}
\hline & $a$ & $b$ & $c$ & $d$ & $e$ & $f$ & $g$ & $h$ & $i$ & $j$ & $k$ & $l$ & $m$ & $n$ & $o$ & $p$ \\
\hline$a$ & 1 & 0,193 & 0,096 & 0,096 & 0,11 & 0,129 & 0,193 & 0,11 & 0,11 & 0,257 & 0,154 & 0,096 & 0,11 & 0,11 & 0,096 & 0,11 \\
$b$ & 0,017 & 1 & 0,019 & 0,019 & 0,022 & 0,025 & 0,038 & 0,022 & 0,022 & 0,051 & 0,03 & 0,019 & 0,022 & 0,022 & 0,019 & 0,022 \\
$c$ & 0,068 & 0,152 & 1 & 0,076 & 0,087 & 0,102 & 0,152 & 0,087 & 0,087 & 0,203 & 0,122 & 0,076 & 0,087 & 0,087 & 0,076 & 0,087 \\
$d$ & 0,068 & 0,152 & 0,076 & 1 & 0,087 & 0,102 & 0,152 & 0,087 & 0,087 & 0,203 & 0,122 & 0,076 & 0,087 & 0,087 & 0,076 & 0,087 \\
$e$ & 0,052 & 0,117 & 0,058 & 0,058 & 1 & 0,078 & 0,117 & 0,067 & 0,067 & 0,156 & 0,093 & 0,058 & 0,067 & 0,067 & 0,058 & 0,067 \\
$f$ & 0,038 & 0,086 & 0,043 & 0,043 & 0,049 & 1 & 0,086 & 0,049 & 0,049 & 0,114 & 0,069 & 0,043 & 0,049 & 0,049 & 0,043 & 0,049 \\
$g$ & 0,017 & 0,038 & 0,019 & 0,019 & 0,022 & 0,025 & 1 & 0,022 & 0,022 & 0,051 & 0,03 & 0,019 & 0,022 & 0,022 & 0,019 & 0,022 \\
$h$ & 0,052 & 0,117 & 0,058 & 0,058 & 0,067 & 0,078 & 0,117 & 1 & 0,067 & 0,156 & 0,093 & 0,058 & 0,067 & 0,067 & 0,058 & 0,067 \\
$i$ & 0,052 & 0,117 & 0,058 & 0,058 & 0,067 & 0,078 & 0,117 & 0,067 & 1 & 0,156 & 0,093 & 0,058 & 0,067 & 0,067 & 0,058 & 0,067 \\
$j$ & 0,01 & 0,021 & 0,011 & 0,011 & 0,012 & 0,014 & 0,021 & 0,012 & 0,012 & 1 & 0,017 & 0,011 & 0,012 & 0,012 & 0,011 & 0,012 \\
$k$ & 0,026 & 0,06 & 0,03 & 0,03 & 0,034 & 0,04 & 0,06 & 0,034 & 0,034 & 0,079 & 1 & 0,03 & 0,034 & 0,034 & 0,03 & 0,034 \\
$l$ & 0,068 & 0,152 & 0,076 & 0,076 & 0,087 & 0,102 & 0,152 & 0,087 & 0,087 & 0,203 & 0,122 & 1 & 0,087 & 0,087 & 0,076 & 0,087 \\
$m$ & 0,052 & 0,117 & 0,058 & 0,058 & 0,067 & 0,078 & 0,117 & 0,067 & 0,067 & 0,156 & 0,093 & 0,058 & 1 & 0,067 & 0,058 & 0,067 \\
$n$ & 0,052 & 0,117 & 0,058 & 0,058 & 0,067 & 0,078 & 0,117 & 0,067 & 0,067 & 0,156 & 0,093 & 0,058 & 0,067 & 1 & 0,058 & 0,067 \\
$o$ & 0,068 & 0,152 & 0,076 & 0,076 & 0,087 & 0,102 & 0,152 & 0,087 & 0,087 & 0,203 & 0,122 & 0,076 & 0,087 & 0,087 & 1 & 0,087 \\
$p$ & 0,052 & 0,117 & 0,058 & 0,058 & 0,067 & 0,078 & 0,117 & 0,067 & 0,067 & 0,156 & 0,093 & 0,058 & 0,067 & 0,067 & 0,058 & 1 \\
\hline
\end{tabular}

Table 10. Fuzzy relative intensity matrix

\begin{tabular}{ccccccccccccccccccc}
\hline & $a$ & $b$ & $c$ & $d$ & $e$ & $f$ & $g$ & $h$ & $i$ & $j$ & $k$ & $l$ & $m$ & $n$ & $o$ & $p$ \\
\hline$a$ & 1 & 0,193 & 0,096 & 0,096 & 0,110 & 0,129 & 0,193 & 0,110 & 0,110 & 0,257 & 0,154 & 0,096 & 0,110 & 0,110 & 0,096 & 0,110 \\
$d$ & 0,068 & 0,152 & 0,076 & 1 & 0,087 & 0,102 & 0,152 & 0,087 & 0,110 & 0,203 & 0,122 & 0,076 & 0,087 & 0,087 & 0,087 & 0,087 \\
$c$ & 0,068 & 0,152 & 1 & 0,076 & 0,087 & 0,102 & 0,152 & 0,087 & 0,087 & 0,203 & 0,122 & 0,076 & 0,087 & 0,087 & 0,087 & 0,087 \\
$l$ & 0,068 & 0,152 & 0,076 & 0,076 & 0,087 & 0,102 & 0,152 & 0,087 & 0,087 & 0,203 & 0,122 & 1 & 0,087 & 0,087 & 0,087 & 0,087 \\
$o$ & 0,068 & 0,152 & 0,076 & 0,076 & 0,087 & 0,102 & 0,152 & 0,087 & 0,087 & 0,203 & 0,122 & 0,076 & 0,087 & 0,087 & 1 & 0,087 \\
$m$ & 0,068 & 0,117 & 0,076 & 0,076 & 0,087 & 0,087 & 0,117 & 0,076 & 0,087 & 0,156 & 0,093 & 0,076 & 1 & 0,087 & 0,087 & 0,087 \\
$e$ & 0,067 & 0,117 & 0,067 & 0,067 & 1 & 0,078 & 0,117 & 0,067 & 0,067 & 0,156 & 0,093 & 0,067 & 0,067 & 0,067 & 0,067 & 0,067 \\
$h$ & 0,067 & 0,117 & 0,067 & 0,067 & 0,067 & 0,078 & 0,117 & 1 & 0,067 & 0,156 & 0,093 & 0,067 & 0,067 & 0,067 & 0,067 & 0,067 \\
$n$ & 0,067 & 0,117 & 0,067 & 0,067 & 0,067 & 0,078 & 0,117 & 0,067 & 0,067 & 0,156 & 0,093 & 0,067 & 0,067 & 1 & 0,067 & 0,067 \\
$p$ & 0,067 & 0,117 & 0,067 & 0,067 & 0,067 & 0,078 & 0,117 & 0,067 & 0,067 & 0,156 & 0,093 & 0,067 & 0,067 & 0,067 & 0,067 & 1 \\
$i$ & 0,067 & 0,117 & 0,067 & 0,067 & 0,067 & 0,040 & 0,117 & 0,067 & 1 & 0,156 & 0,093 & 0,067 & 0,067 & 0,067 & 0,067 & 0,067 \\
$f$ & 0,049 & 0,086 & 0,049 & 0,049 & 0,049 & 1 & 0,086 & 0,049 & 0,049 & 0,114 & 0,069 & 0,049 & 0,049 & 0,049 & 0,049 & 0,049 \\
$k$ & 0,040 & 0,060 & 0,040 & 0,040 & 0,040 & 0,040 & 0,060 & 0,040 & 0,040 & 0,079 & 1 & 0,040 & 0,040 & 0,040 & 0,040 & 0,040 \\
$g$ & 0,030 & 0,038 & 0,030 & 0,030 & 0,030 & 0,030 & 1 & 0,030 & 0,030 & 0,051 & 0,030 & 0,030 & 0,030 & 0,030 & 0,030 & 0,030 \\
$b$ & 0,030 & 1 & 0,030 & 0,030 & 0,030 & 0,030 & 0,038 & 0,030 & 0,030 & 0,051 & 0,030 & 0,030 & 0,030 & 0,030 & 0,030 & 0,030 \\
$j$ & 0,021 & 0,021 & 0,021 & 0,021 & 0,021 & 0,021 & 0,021 & 0,021 & 0,021 & 1 & 0,021 & 0,021 & 0,021 & 0,021 & 0,021 & 0,021 \\
\hline
\end{tabular}

\subsection{Analysis of results}

Fuzzy matrices show how ambiguity and fuzziness of stakeholders and a subjective appraisal of the decision maker can be managed. Fuzzy matrices of $\mathrm{FRI}_{\mathrm{M}}$ and $\mathrm{FRIn} \mathrm{n}_{\mathrm{M}}$ for each stakeholder are obtained from the dominant eigenvalue and eigenvector. Each matrix takes into account that the relationship of each stakeholder with itself is total, i.e., all vertices have loops equals 1 . 
First, the values, colours and a semantic scale used to show the intensity of relationships, representing the different degrees of intensity, need to be defined. According to the scale, if there is a significantly intense relationship represented by the value of 10, it is highlighted in green colour and implies that the respective stakeholder is very powerful/influential. On the other hand, a moderately intense relationship is represented by values between 6 and 9, is highlighted in colours ranging from greenish yellow to light green, and implies that the stakeholder has substantial power/influence. An equally intense relationship is represented by the value of 5, is highlighted in yellow colour and implies that both parties are equally powerful/influential. Similarly, a relationship of weak intensity could be represented by a value between 4 and 1, is highlighted in colours ranging between light yellow and light orange, and implies a low level of power/influence. Finally, a relationship with an insignificant intensity relationship is represented by the value of 0 , is highlighted in orange colour, and implies a negligible level of power/influence. Therefore, a stakeholder shown in a colour nearest to orange possesses the lowest intensity of power. Several intensity relations are shown according to this scale.

Table 11. Scale of intensity degree

\begin{tabular}{|c|c|c|}
\hline Value scale & Colour scale & Semantic scale \\
\hline 10 & & Huge powerful/influential \\
\hline 9 & & Practically to be powerful/influential \\
\hline 8 & & Almost to be powerful/influential \\
\hline 7 & & Quite to be powerful/influential \\
\hline 6 & & More to be powerful/influential \\
\hline 5 & & Equally to be powerful/influential \\
\hline 4 & & Fewer to be powerful/influential \\
\hline 3 & & Partly to be powerful/influential \\
\hline 2 & & Almost without to be powerful/influential \\
\hline 1 & & Far to be powerful/influential \\
\hline 0 & & Tiny power/influence \\
\hline
\end{tabular}

The fuzzy matrix $\mathrm{FRIn}_{\mathrm{M}}$ is shown according to the above scale, illustrating the power/influence relationship intensity of each stakeholder (see Figure 1). First, the figure shows the ranking of the intensity of relationships in descending order, where $a$ has a significantly and moderately intense relationship, indicating its huge power/influence over others. Similarly, it is seen that stakeholders, $d, c, l, o$ and $m$ have a moderately intense relationship, indicating a certain amount of influence due to the power exercised. On the other hand, it is seen that stakeholders $e, h, n, p$ and $i$ have a moderately and weakly intense relationship, indicating a lower power/influence over others. Finally, $f, k, g, b$ and $j$ have an insignificantly intense relationship, indicating a negligible amount of power/influence. Thus, results show to the differences in the analysis depending on the appraisal by the CEO of the available information.

Figure 1. Depict of relative intensity of the relationships

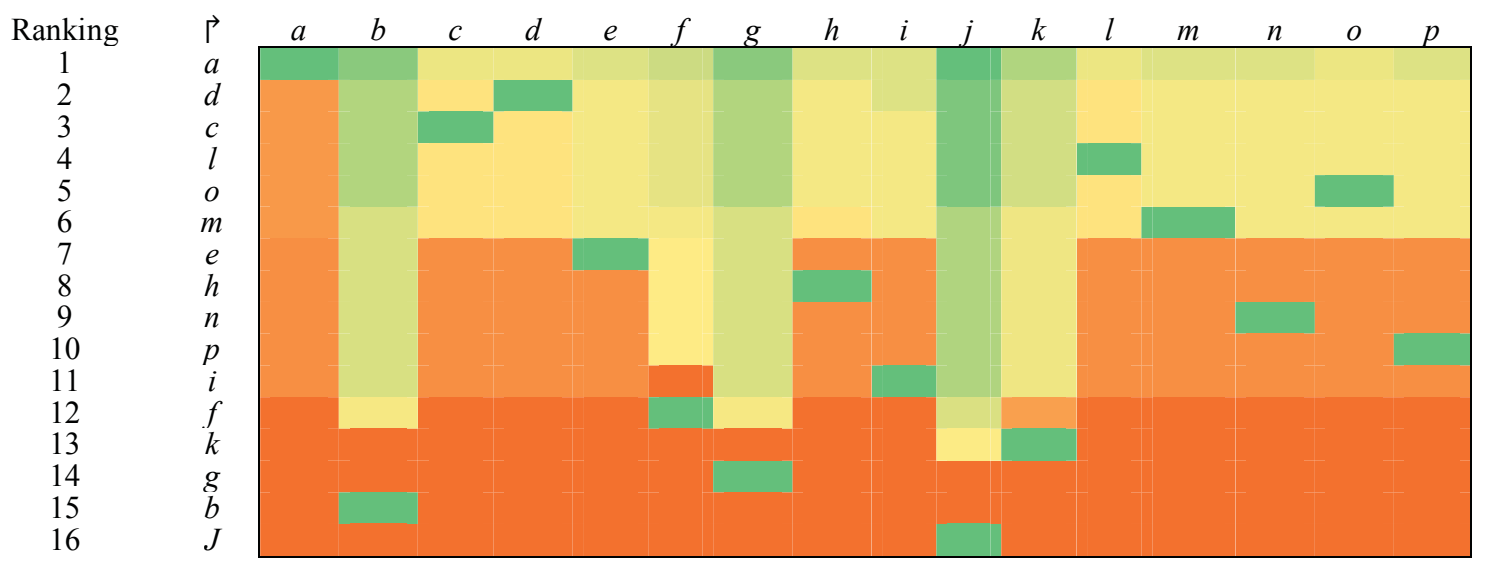


Figure 2 shows ordered relationships of the fuzzy matrix $\mathrm{FRI}_{\mathrm{M}}$ to illustrate the dynamic relationships between stakeholders. The ordered relationship is given by $\alpha=0.07$, considered as the threshold for the desired level of importance. In this case, the importance of grouping of indifferent elements (IE) is highlighted, as there are several groups of IE and a single closed loop. On the one hand, a circuit between several stakeholders $b, c, l, m$ and $o$ is observed, which is explained as an equivalency class or a set of strongly connected relations (Gil-Aluja, 1999). Indeed, linking relationships and an equivalency class denote the incidence, importance and intensity of relations for each vertex. On the other hand, the figure shows unidirectional relations from $a$ and a closed loop, containing $e, i, h, n, p, f, k, b, j$ and $g$, which are explained as a relation of significantly stronger influence over others. Furthermore, it shows several levels, where level 1 is the most influential and level 6 is the least influential, in turn, illustrating the position of power of each category within the system. Therefore, the levels of incidence and importance can be weakened and strengthened.

Figure 2. Graph of the relative importance of the relationships

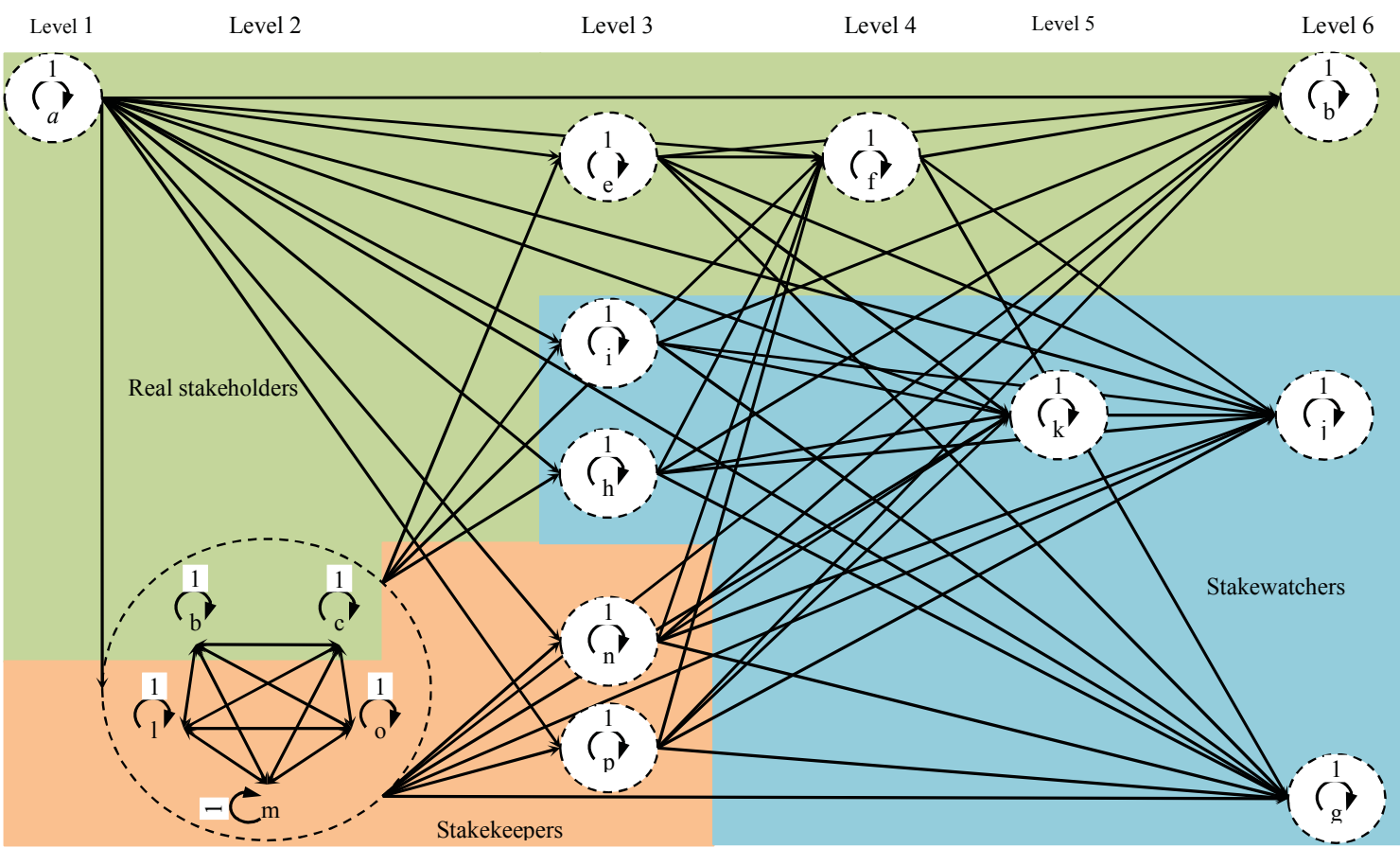

In conclusion, using this tool, we have compared and related each stakeholder to obtain the relative intensity and importance of relationships among them. On the one hand, the relative intensity is given by fuzzy matrix $\mathrm{FRIn}_{\mathrm{M}}$, which depicts the relationships among each stakeholder through scale of intensity degree. This scale considers three ways of evaluating intensity, i.e., value, colour and semantic, allowing a better understanding of the relative intensity relationships. On the other hand, the relative importance is given by fuzzy matrix $\mathrm{FRI}_{\mathrm{M}}$, which shows graphically ordered relationships using the $\alpha$ value as a threshold for the desired level of importance. Additionally, influential levels are shown in descending order.

\subsection{Implications and limitations}

The proposed mathematical approximation provides a novel tool for the analysis of dynamic and uncertain processes involved in changing relationships between stakeholders. Indeed, other tools have been developed within stakeholder theory to evaluate the environment and identify the relationships between 
groups of stakeholders (Wagner et al., 2011). Among such tools, particularly prominent are the multicriteria decision-making tool (Holz et al., 2006), the stakeholder analysis tool (Bourne and Walker, 2005), the network approach to interactions of stakeholders (Rowley and Moldoveanu, 2003; Rowley, 1997), cognitive mapping of stakeholders' mental models (Hjortsø et al., 2005), analysis of conflicts (Memon and Wilson, 2007), the multi-criteria analysis technique (MCAT) (Finn et al., 2009) and the Q methodology (Wolsink and Breukers, 2010). Such tools have difficulty defining boundaries and identifying the relevant stakeholders (Ramirez, 1999).

Accordingly, the main implication of the proposed approach is taking into account the importance of

information to establish the boundaries and relationships of each characteristic according to its intensity. Additionally, it performs multiple comparisons between each characteristic of the information. The interests and opinions of decision makers can be parameterised. A mathematical application shows how each interest group could be classified and related according to subjective information. Similarly, relationships established between stakeholders are determined by power/influence and the position of each agent within the relationship network. Furthermore, dynamics of such relationships not only encourage competition but also contribute to improved competitiveness and productivity by fostering cooperation and the transfer of knowledge, and strengthening trust between the interested parties and the ties among them according to power/influence positions. Thus, a position of influence refers to groups or individuals that can affect or be affected by the organization, according to pragmatic aspects of the relationship between the stakeholders and the firm, i.e., a relationship determined by the market (Fassin, 2009; Freeman, 2011). Multiple relationships have a high degree of variation in the intensity of power/influence that can be explained by heterogeneity. Accordingly, the analysis focuses on the dynamics and the intensity of a relationship, which imply how stakeholders can affect or be affected by decisions or actions of an organisation within a dynamic and uncertain environment, resulting from factors such as globalization, improvements in information technology systems and technological changes.

For example, Apple Inc. is an American multinational company in the technology sector that designs and manufactures electronic equipment, software and online services and enjoys a significant presence and prestige worldwide due to the quality of its products and services. At the end of 2017, Apple Inc. faced customer complaints related to a slowdown of mobile devices. In this case, two agents, i.e., the customers and the company, are involved, with the relationship dynamics affected by company's decisions. The interactions also involve the third regulatory agent, namely, the government, which must protect the interests of society. Thus, the power/influence intensity and the dynamics of the relationship among the customers, the company and the government cause their respective positions to change, causing the ties to be in continuous tension and maintaining strong positions among the stakeholders. This situation has short-term effects that are not predictable. Likewise, the intensity of relations between agents is more dynamic from their positions of power where public opinion determines the effect on the reputation. Hence, the intensity and importance of the relationships is relative.

On the other hand, the primary limitations are in the empirical validation of the research itself, due to presenting a methodological proposal with a mathematical application. Similarly, there are methodological limitations, as subsequent to a mathematical proposition, a hypothetical example is shown to illustrate the operation of algorithms and in this case, to show how the subjectivity of decision-makers is parameterized. Additionally, such methodological limitations are clear, as we use as an example the power/influence relationships that exist between stakeholders, studied by the stakeholder theory. Thus, given the stated theoretical assumptions, a methodology has been proposed that tries to capture the impacts of the dynamic interaction between the environment and the companies. 


\section{Conclusions}

We have focused on studying dynamic interactions of stakeholders to explain how a set of agents can act by considering the power/influence positions. We have considered the models of Freeman (1984), Donaldson and Preston (1995), Jones (1995), Frooman (1999), Friedman and Miles (2006), Fassin (2009), Savage et al. (2011) and Wagner et al. (2012), that present various analysis methods that explain the relations of the stakeholders. Similarly, we have studied the literature on the decision-making under uncertainty, which offers a wide range of methods for processing subjective and objective information, personal preferences, attitudes and the resulting data. Based on the above, we have proposed a novel tool to analyse dynamic interactions for evaluating stakeholder dynamics through power relationships. This application uses the importance of characteristics algorithm in combination with composition max-min to compare, group and order information. Thus, a combination of these techniques can represent a holistic appraisal of the firm's immediate environment according to the relative level of importance. The method is called relative importance and relative intensity of characteristics.

We have developed a hypothetical mathematical example to show the feasibility and usefulness of this tool for evaluating dynamics of stakeholder relationships through power relationships. This tool allows comparing and relating each stakeholder, resulting in the relative intensity and importance of relationships among them. The relative intensity is given by a fuzzy matrix FRIn $\mathrm{M}_{\mathrm{M}}$ that describes the relationships among all stakeholders in terms of a scale of variable intensity. Such a scale presents three ways of evaluating the intensity, namely, as a value, a colour and a semantic expression, allowing a better understanding of a relative intensity relationship. The relative importance is represented by the fuzzy matrix $\mathrm{FRI}_{\mathrm{M}}$, showing a graphically ordered relationship from $\alpha$ value as the threshold for the desired level of importance. Additionally, the influential levels are shown in the descending order. Thus, it is noteworthy that the proposed tool determines the boundaries and the relationship between each characteristic according to the intensity through multiple comparisons, taking into account the importance of information. Furthermore, it is shown each interest group could be classified and related according to the subjective information, the interests and opinions of the decision makers. Furthermore, it is noted that the relationships established between stakeholders are determined by power/influence and the position that each agent occupies within the network of relationships.

However, the methodological proposal has limitations due to the nature of this research, based on theoretical assumptions regarding stakeholders and the use of a hypothetical example to show the operation of algorithms. The theoretical assumptions include the focus on the position of influence referring to agents that can affect or be affected by other agents and the environment. A hypothetical mathematical proposition shows the operation of algorithms, which in this case seeks to show how the subjectivity of decision makers is parameterized. Thus, the primary limitation concerns the empirical validation of the research itself.

Finally, the importance of a relation can be shown by different degrees of intensity. Therefore, the proposed method enables us to analyse the firm's immediate environment, according to the appraisal of the CEO. Application of this novel method to strategic problems in business, such as planning management, strategy management, business ethics and corporate responsibility, can be considered. Similarly, in future research, we can explore and develop new extensions of this method by combining it with other techniques, e.g., aggregation operators or distance measures, offering the possibility to aggregate and compare information.

\section{Acknowledgements}

Project supported by "Red Iberoamericana para la Competitividad, Innovación y Desarrollo" (REDCID) project number 616RT0515 in "Programa Iberoamericano de Ciencia y Tecnología para el 
Desarrollo" (CYTED). José M. Merigó acknowledges support from the Chilean Government through Conicyt and the Fondecyt Regular program (project number 1160286).

\section{REFERENCES}

Blanco-Mesa, F. (2015), Técnicas para la toma de decisiones en contextos inciertos: identificación de oportunidades socioeconómicas en el ámbito deportivo, Universitat de Barcelona.

Blanco-Mesa, F., Gil-Lafuente, A.M. and Merigó, J.M. (2018), "New aggregation operators for decision-making under uncertainty: an applications in selection of entrepreneurial opportunities", Technological and Economic Development of Economy, Vol. 24 No. 2, pp. 335-357.

Blanco-Mesa, F. and Gil-Lafuente, A.M. (2017), "Towards a competitiveness in the economic activity in Colombia: Using Moore's families and Galois latticies in clustering", Economic Computation and Economic Cybernetics Studies and Research, Vol. 51 No. 3, pp. 231-250.

Blanco-Mesa, F.R. and Gil-Lafuente, A.M. (2014), "Characterization and grouping of the Colombia regions for development of clusters: An application of the Pichat algorithm", Journal of Computational Optimization in Economics and Finances, Vol. 5 No. 3, pp. 187-196.

Bourne, L. and Walker, D.H.T. (2005), “Visualising and mapping stakeholder influence”, Management Decision, Vol. 43 No. 5 , pp. 649-660.

Donaldson, T. and Preston, L.E. (1995), "The stakeholder theory of the corporation: Concepts, evidence and implications.", Academy of Management Review, Academy of Management, Vol. 20 No. 1, pp. 65-91.

Emrouznejad, A. and Marra, M. (2014), "Ordered weighted averaging operators 1988-2014: A citation-based literature survey", International Journal of Intelligent Systems, Vol. 29 No. 11, pp. 994-1014.

Fassin, Y. (2007), "Imperfections and shortcomings of the stakeholder model's graphical representation", Journal of Business Ethics, Vol. 80 No. 4, pp. 879-888.

Fassin, Y. (2009), “The stakeholder model refined”, Journal of Business Ethics, Vol. 84 No. 1, pp. $113-135$.

Fassin, Y. (2010), “A dynamic perspective in Freeman's stakeholder model”, Journal of Business Ethics, Vol. 96 No. S1, pp. 39 49.

Finn, J.A., Bartolini, F., Bourke, D., Kurz, I. and Viaggi, D. (2009), "Ex post environmental evaluation of agri-environment schemes using experts' judgements and multicriteria analysis”, Journal of Environmental Planning and Management, Routledge, Vol. 52 No. 5, pp. 717-737.

Freeman, R.E. (1984), Strategic Management : A Stakeholder Approach, Pitman, Boston.

Freeman, R.E. (2004), “The stakeholder approach revisited”, Zeitschrift Für Wirtschafts- Und Unternehmensethik, Vol. 5 No. 3 , pp. $228-241$.

Freeman, R.E. (2011), “Managing for stakeholders: Trade-offs or value creation”, Journal of Business Ethics, Vol. 96 No. S1, pp. 7-9.

Friedman, A.L. and Miles, S. (2002), “Developing stakeholder theory”, Journal of Management Studies, Vol. 39 No. 1, pp. 1-21.

Friedman, A.L. and Miles, S. (2006), "Analityc stakeholders theorizing”, in Friedman, A.L. and Miles, S. (Eds.), Stakeholders: Theory and Practice, Oxford University Press, Oxford, pp. 83-116.

Frooman, J. (1999), "Stakeholder influence strategies”, The Academy of Management Review, Vol. 24 No. 2, pp. $191-205$.

Gil-Aluja, J. (1999), Elements for a Theory of Decision in Uncertainty, Kluwer Academic Publishers, Dordrecht.

Gil-Aluja, J. (2000), “Lances y desventuras del nuevo paradigma de la teoría de la decisión”, Proceedings Del III Congreso SIGEF, SIGEF, Buenos Aires, pp. 11-37.

Gil-Lafuente, A.M. and Barcellos de Paula, L. (2010), "Una aplicación de la metodología de los efectos olvidados: Los factores que contribuyen al crecimiento sostenible de la empresa", Cuadernos del CIMBAGE, Vol. 12, pp. 23-34.

Gil-Lafuente, A.M. and Barcellos de Paula, L. (2013), “Algorithm applied in the identification of stakeholders", Kybernetes, Vol. 42 No. 5, pp. 674-685. 
Gil-Lafuente, A.M., Klimova, A. and Imanov, K. (2012), "Forgotten effects in the comparative economic analysis for Spain and Russia in conditions of globalization", 2012 IV International Conference "Problems of Cybernetics and Informatics" (PCI), IEEE, Baku, pp. 1-4.

Gil-Lafuente, A.M. and Luis Bassa, C. (2011), “The forgotten effects model in a CRM strategy”, Fuzzy Economic Review, Vol. 16 No. 1 , pp. 3-19.

Gil-Lafuente, A.M. and Merigó, J.M. (2007), “The ordered weighted averaging distance operator", Lectures on Modelling and Simulation, Vol. 8 No. 1, pp. 84-95.

Gil-Lafuente, A.M., Merigó, J.M. and Xu, Y.J. (2013), “Decision making with induced aggregation operators and the adequacy coefficient", Economic Computation and Economic Cybernetics Studies and Research, No. 1, pp. 185-202.

Gil-Lafuente, J. (1997), Marketing para el Nuevo Milenio: Nuevas Técnicas para la Gestión Comercial en la Incertidumbre, Ediciones Pirámide, Barcelona.

Gil-Lafuente, J. (2001), “Algoritmos para la Excelencia: Claves para el Éxito en la Gestión Deportiva”.

Gil-Lafuente, J. (2002), Keys for Success in Sport Management, Ed. Malladoiro, Vigo.

Gil-Lafuente, J. (2008), "Automatismos y Racionalidad en la Toma de Decisiones para Sustituir a un Deportista en Momentos decisivos", Cuadernos de gestión, Instituto de Economía Aplicada a la Empresa, Vol. 8 No. 1, pp. 39-57.

Gil-Lafuente, A.M., Blanco, F.R. and Castillo, C. (2012), "Forgotten effects of sport", in Gil-Lafuente, A.M., Gil-Lafuente, J. and Merigó-Lindahl, J.M. (Eds.), Soft Computing in Management and Business Economics, Vol. 287, Springer Berlin Heidelberg, pp. 375-391.

Herrera, F. (1995), “A sequential selection process in group decision making with a linguistic assessment approach", Information Sciences, Vol. 85 No. 4, pp. 223-239.

Herrera, F. and Martinez, L. (2000), "A 2-tuple fuzzy linguistic representation model for computing with words”, IEEE Transactions on Fuzzy Systems, Vol. 8 No. 6, pp. 746-752.

Hjortsø, C.N., Christensen, S.M. and Tarp, P. (2005), "Rapid stakeholder and conflict assessment for natural resource management using cognitive mapping: The case of Damdoi Forest Enterprise, Vietnam", Agriculture and Human Values, Vol. 22 No. 2, pp. 149-167.

Holz, L., Kuczera, G. and Kalma, J. (2006), “Multiple criteria decision making: Facilitating a learning environment”, Journal of Environmental Planning and Management, Vol. 49 No. 3, pp. 455-470.

Jones, T.M. (1995), "Instrumental stakeholders theory: A synthesis of ethics and economics", The Academy of Management Review, Vol. 20 No. 2, pp. 404-437.

Kaufmann, A. and Gil-Aluja, J. (1986), Introducción de la Teoría de los Subconjuntos Borrosos a la Gestión de las Empresas, Milladoiro, Santiago de Compostela.

Kaufmann, A. and Gil-Aluja, J. (1987), Técnicas Operativas de Gestión para el Tratamiento de la Incertidumbre, Hispano Europea, Barcelona.

Kaufmann, A. and Gil-Aluja, J. (1988), Models per a la Recerca d'Efectes Oblidats, Milladoiro, Vigo.

Kaufmann, A. and Gil-Aluja, J. (1993), Técnicas Especiales para la Gestión de Expertos, Villadoiro, Vigo.

Kaufmann, A. and Gil-Aluja, J. (1995), Grafos Neuronales para la Economía y la Gestión de Empresas, Ediciones Pirámide, Madrid.

Kaufmann, A., Gil-Aluja, J. and Gil-Lafuente, A.M. (1994), La Creatividad en la Gestión de las Empresas, Ediciones Pirámide.

León-Castro, E., Áviles-Ochoa, E. and Gil-Lafuente, A.M. (2016), "Exchange rate usd/mxn forecast through econometric models, time series and howma operators", Economic Computation and Economic Cybernetics Studies and Research, Vol. 50 No. 4, pp. 135-150.

León-Castro, E., Avilés-Ochoa, E. and Merigó, J.M. (2017), "Induced heavy moving averages”, International Journal of Intelligent Systems, available at:https://doi.org/10.1002/int.21916.

Maqueda Lafuente, J.F., Gil-Lafuente, A.M., Guzman-Parra, V.F. and Gil-Lafuente, J. (2013), "Key factors for entrepreneurial success", Management Decision, Vol. 51 No. 10, pp. 1932-1944. 
Memon, P.A. and Wilson, G.A. (2007), "Contesting governance of indigenous forests in New Zealand: The case of the West Coast Forest Accord", Journal of Environmental Planning and Management, Vol. 50 No. 6, pp. 745-764.

Merigó, J.M. (2009), Nuevas extensiones a los operadores owa y su aplicación en los métodos de decisión, Universitat de Barcelona.

Merigó, J.M. (2011), “A unified model between the weighted average and the induced OWA operator”, Expert Systems with Applications, Vol. 38 No. 9, pp. 11560-11572.

Merigó, J.M. (2013), "The probabilistic weighted averaging distance and its application in group decision making", Kybernetes, Vol. 42 No. 5, pp. 686-697.

Merigó, J.M. and Gil-Lafuente, A.M. (2008), "On the use of the OWA operator in the Euclidean distance", International Journal of Computer Science and Engineering, Vol. 2 No. 4, pp. 170-176.

Merigó, J.M. and Gil-Lafuente, A.M. (2010), "New decision-making techniques and their application in the selection of financial products", Information Sciences, Vol. 180 No. 11, pp. 2085-2094.

Merigó, J.M. and Gil-Lafuente, A.M. (2011), "Decision-making in sport management based on the OWA operator", Expert Systems with Applications, Vol. 38 No. 8, pp. 10408-10413.

Merigó, J.M., Palacios-Marqués, D. and Benavides-Espinosa, M. del M. (2015), “Aggregation methods to calculate the average price", Journal of Business Research, Vol. 68 No. 7, pp. 1574-1580.

Merigó, J.M., Palacios-Marqués, D. and Zeng, S.Z. (2016), "Subjective and objective information in linguistic multi-criteria group decision making", European Journal of Operational Research, Vol. 248 No. 2, pp. 522-531.

Mitchell, R.K., Agle, B.R. and Wood, D.J. (1997), "Toward a theory of stakeholders identification and salience: Defining the principle of who and what really", The Academy of Management Review, Vol. 22 No. 4, pp. 853-886.

Nicolás, C. and Gil-Lafuente, J. (2012), "Customer experience assessment: Forgotten effects”, Journal of Computational Optimization in Economics and Finance, Vol. 4 No. 2-3, pp. 77-88.

Pérez-Arellano, L.A., León-Castro, E., Avilés-Ochoa, E. and Merigó, J.M. (2017), "Prioritized induced probabilistic operator and its application in group decision making", International Journal of Machine Learning and Cybernetics, Springer Berlin Heidelberg, pp. 1-12.

Ramirez, R. (1999), "Stakeholder analysis and conflict management", in Buckles, D. (Ed.), Cultivating Peace: Conflict and Collaboration in, World Bank Institute, Washintong, pp. 101-126.

Rowley, T.I. and Moldoveanu, M. (2003), "When will stakeholder groups act? An interest and identity: Based model of stakeholder group mobilization", Academy of Management Review, Vol. 28 No. 2, pp. 204-219.

Rowley, T.J. (1997), "Moving beyond dyadic ties: A network theory of stakeholder influences", The Academy of Management Review, Vol. 22 No. 4, pp. 887-910.

Savage, G.T., Bunn, M.D., Gray, B., Xiao, Q., Wang, S., Wilson, E.J. and Williams, E.S. (2011), "Stakeholder collaboration: Implications for stakeholder theory and practice", Journal of Business Ethics, Vol. 96 No. S1, pp. 21-26.

Torra, V. (1997), “The weighted OWA operator”, International Journal of Intelligent Systems, Vol. 12 No. 2, pp. 153-166.

Vizuete-Luciano, E., Gil-Lafuente, A.M., García-González, A., Boria-Reverter, S. (2013), "Forgotten effects of corporate social and environmental responsibility", Kybernetes, Vol. 42 No. 5, pp. 736-753.

Wagner, E., Alves, H. and Raposo, M. (2011), "Stakeholder theory: Issues to resolve”, Management Decision, Vol. 49 No. 2, pp. $226-252$.

Wagner, E., Alves, H. and Raposo, M. (2012), "A model for stakeholder classification and stakeholder relationships", Management Decision, Vol. 50 No. 10, pp. 1861-1879.

Wei, G. (2009), "Uncertain lingustic hybrid geometric mean operator and its applications to group decision making under uncertain linguistic environment”, International Journal of Uncertainty, Fuzziness and Knowledge-Based Systems, Vol. 17 No. 2, pp. 251-267.

Windsor, D. (2011), "The role of dynamics in stakeholder thinking”, Journal of Business Ethics, Vol. 96 No. S1, pp. $79-87$.

Wolsink, M. and Breukers, S. (2010), "Contrasting the core beliefs regarding the effective implementation of wind power. An 
international study of stakeholder perspectives”, Journal of Environmental Planning and Management, Vol. 53 No. 5, pp. $535-558$.

Xu, Z.S. and Da, Q.L. (2003), “An overview of operators for aggregating information”, International Journal of Intelligent Systems, Vol. 18 No. 9, pp. 953-969.

Yager, R.R. (1988), “On ordered weighted averaging aggregation operators in multicriteria decision making”, IEEE Transactions on Systems, Man, and Cybernetics, Vol. 18 No. 1, pp. 183-190.

Yager, R.R., Kacprzyk, J. and Beliakov, G. (2011), Recent Developments in the Ordered Weighted Averaging Operators: Theory and Practice, Studies in Fuzziness and Soft Computing, Vol. 265, Springer Science \& Business Media., Berlin, Heidelberg.

Zeng, S.Z., Su, W. and Le, A. (2012), "Fuzzy generalized ordered weighted averaging distance operator and its application to decision making", International Journal of Fuzzy Systems, Vol. 14 No. 3, pp. 402-412. 